\title{
Dose escalation of 3D radiotherapy is effective for esophageal squamous cell carcinoma: a multicenter retrospective analysis (3JECROG R-03)
}

\author{
Wencheng Zhang ${ }^{1 \#}$, Jingjing Zhao ${ }^{1 \#}$, Weiming Han ${ }^{2}$, Hualei Zhang ${ }^{1}$, Xin Wang ${ }^{2}$, Chen Li $^{2}$, \\ Junqiang Chen ${ }^{3}$, Xiaomin Wang ${ }^{4}$, Yidian Zhao ${ }^{4}$, Xueying Qiao ${ }^{5}$, Zhiguo Zhou ${ }^{5}$, Chun Han ${ }^{5}$, Shuchai Zhu ${ }^{5}$,

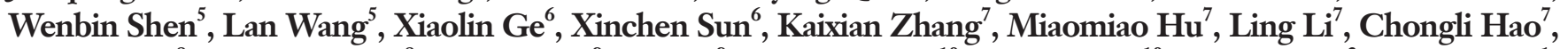 \\ Gaofeng $\mathrm{Li}^{8}$, Yonggang $\mathrm{Xu}^{8}$, Yadi Wang ${ }^{9}, \mathrm{Na} \mathrm{Lu}^{9}$, Miaoling Liu ${ }^{10}$, Shuai Qian ${ }^{10}$, Zefen Xiao ${ }^{2}$, Ping Wang ${ }^{1}$, \\ Qingsong Pang ${ }^{1}$
}

${ }^{1}$ Department of Radiation Oncology, Tianjin Medical University Cancer Institute and Hospital, National Clinical Research Center for Cancer, Key Laboratory of Cancer Prevention and Therapy, Tianjin, Tianjin's Clinical Research Center for Cancer, Tianjin, China; ${ }^{2}$ Department of Radiation Oncology, National Cancer Center/National Clinical Research Center for Cancer/Cancer Hospital, Chinese Academy of Medical Sciences and Peking Union Medical College, Beijing, China; ${ }^{3}$ Department of Radiation Oncology, Fujian Cancer Hospital/Fujian Medical University Cancer Hospital, Fuzhou, China; ${ }^{4}$ Department 4th of Radiation Oncology, Anyang Cancer Hospital, Anyang, China; ${ }^{5}$ Department of Radiation Oncology, the Fourth Hospital of Hebei Medical University, Shijiazhuang, China; ${ }^{6}$ Department of Radiation Oncology, the First Affiliated Hospital of Nanjing Medical University, Nanjing, China; ${ }^{7}$ Department of Oncology, Tengzhou Central People's Hospital, Tengzhou, China; ${ }^{8}$ Department of Radiation Oncology, Beijing Hospital, National Center of Gerontology, Beijing, China; ${ }^{9}$ Department of Radiation Oncology, The Seventh Medical Center of PLA General Hospital, Beijing, China; ${ }^{10}$ Department of Radiation Oncology, Affiliated Hospital of Hebei University, Baoding, China

Contributions: (I) Conception and design: Q Pang, P Wang, Z Xiao; (II) Administrative support: Q Pang, P Wang, Z Xiao; (III) Provision of study materials or patients: Q Pang, P Wang, Z Xiao, C Han; (IV) Collection and assembly of data: W Zhang, J Zhao, H Zhang; (V) Data analysis and interpretation: W Zhang, J Zhao, W Han; (VI) Manuscript writing: All authors; (VII) Final approval of manuscript: All authors.

"These authors contributed equally to this work.

Correspondence to: Qingsong Pang, MD. Department of Radiation Oncology, Tianjin Medical University Cancer Institute and Hospital, Huanhu West Road, Hexi District, Tianjin, China. Email: pangqingsong@tjmuch.com; Ping Wang, MD. Department of Radiation Oncology, Tianjin Medical University Cancer Institute and Hospital, Huanhu West Road, Hexi District, Tianjin, China. Email: wangping@tjmuch.com; Zefen Xiao, MD. Department of Radiation Oncology, National Cancer Center/National Clinical Research Center for Cancer/Cancer Hospital, Chinese Academy of Medical Sciences and Peking Union Medical College, Beijing, China. Email: xiaozefen@sina.com.

Background: To evaluate the impact of radiation dose escalation on overall survival (OS) in patients with non-metastatic esophageal squamous cell carcinoma (ESCC) treated with radical radiotherapy.

Methods: The clinical data of ESCC patients treated with three-dimensional (3D) radiotherapy alone or chemoradiotherapy were collected from multiple institutes and retrospectively analyzed. Patients who received radiation dose $\geq 40$ Gy were included. Radiation dose as a continuous variable was entered into the Cox regression model by using penalized spline regression to allow for a nonlinear relationship between radiation dose and OS to be identified. Patients were stratified into five groups according to $\mathrm{EQD}_{2}$. The Kaplan-Meier method was used to assess the OS in different dose groups. Univariate and multivariate analyses were performed to evaluate the factors associated with OS.

Results: A total of 2,469 patients were included from 10 institutes across China. The median follow-up time was 58.3 months [95\% confidence interval (CI): 56.4-60.2 months]. The median OS and PFS time were 24.3 months (95\% CI: 22.5-26.2 months) and 18.0 months (95\% CI: 16.4-19.6 months), respectively. The risk of death decreased sharply with a dose up to 60 to $62 \mathrm{~Gy}$, before increasing slightly after the dose was elevated beyond 62 Gy. Multivariate analysis indicated that the chance of death was significantly decreased in patients who received radiotherapy doses of 60-62 Gy [P=0.028, hazard ratio (HR) 0.85, 95\% CI: 0.73-0.98)], compared with those who received radiotherapy doses of 40-60 Gy.

Conclusions: Our results reveal radiation dose is a significant prognostic factor of survival for ESCC 
patients. Higher radiation dose contributes to much more favorable survival outcomes for ESCC patients receiving radical radiotherapy by modern techniques, and 60 Gy or above might be the most optimal radiation dose.

Keywords: Esophageal squamous cell carcinoma (ESCC); overall survival (OS); radiation dose

Submitted Feb 15, 2020. Accepted for publication Aug 14, 2020.

doi: 10.21037/atm-20-4672

View this article at: http://dx.doi.org/10.21037/atm-20-4672

\section{Introduction}

Esophageal cancer (EC), as the seventh most frequently diagnosed cancer, was the sixth leading global cause of cancer-associated death in 2018 (1). Surgery is the primary option for treatment of EC at early stage. While accumulated evidence demonstrate that neoadjuvant concurrent chemoradiotherapy followed by surgery yield more favorable survival outcomes compared with surgery alone for EC, with acceptable adverse events $(2,3)$. Unfortunately, due to EC having no obvious symptoms in its early stage, most patients are not eligible for curative surgery at the time of diagnosis. According to the results of the Radiation Therapy Oncology Group (RTOG)-8501 and RTOG 94-05, radical concurrent chemoradiotherapy (CCRT) to a total dose of 50.4 Gy has been accepted as the standard treatment for locally advanced inoperable EC $(4,5)$.

The survival outcome and local control of the tumor of CCRT are still poor, and local failure occurs in about $50 \%$ patients, indicating that the standard radiation dose (50.4 Gy) is inadequate to achieve satisfactory tumor local control (4-7). Moreover, in East Asia, squamous cell carcinoma (SCC) is the predominant histological type of EC and differs from adenocarcinoma in epidemiology, tumor biology, radiation sensitivity, and patterns and sites of recurrence (7-9). With esophageal SCC (ESCC), the local regional recurrence rate is marginally higher (7). Thus, in clinic, a dose of $60 \mathrm{~Gy}$ is more preferred for the definitive CCRT for ESCC in China. However, some studies maintain that dose escalation may lead to high incidence of radiationrelated toxicities, such as esophageal bleeding, perforation, fistula, etc, which is a challenge in the treatment for EC $(10,11)$. Because of these factors, achieving a consensus on the optimal radiation dose for ESCC has been pursued in studies over many years (10-17).

In recent years, the remarkable development in radiation techniques has seen the application of three-dimensional (3D) treatment planning, including intensity-modulated radiation therapy (IMRT), volumetric-modulated arc therapy (VMAT), and helical tomotherapy, which exhibit significantly superior in dose distribution, in numerous countries. Compared to conventional RT techniques, a higher RT dose is selectively delivered to the tumor, while the surrounding normal tissue receives a lower dose $(18,19)$. Consequently, with $3 \mathrm{D}$ radiation therapy, the incidence of radiation-induced toxicities might reduce, and the treatment tolerance might improve. The modern RT techniques provide favorable technical support for the treatment for EC. Several studies have suggested that, with the improvements in RT techniques, dose-escalated RT achieves better local tumor control and more favorable survival outcomes, but opposite arguments also exist $(10,14-17)$. Whether dose escalation of $3 \mathrm{D}$ radiotherapy is safe and effective, especially for ESCC, is still a subject of debate.

Given the discrepancies on the optimal dose for ESCC, we investigated the clinical effects of the RT dose escalation using modern RT techniques to treat of patients with nonoperable ESCC, based on a multi-center database provided by Jing-Jin-Ji Esophageal and Esophagogastric Cancer Radiotherapy and Oncology Group (3JECROG).

We present the following article in accordance with the STROBE reporting checklist (available at http://dx.doi. org/10.21037/atm-20-4672).

\section{Methods}

\section{Data source}

Data, including patients' demographics, disease characteristics, treatment details, tumor control, and survival outcomes, were obtained from 10 medical centers in China. All procedures performed in this study involving human participants were in accordance with the Declaration of Helsinki (as revised in 2013). The study was approved by the Ethics Committee of National Cancer Center/Cancer 
Hospital, Chinese Academy of Medical Sciences and Peking Union Medical College (No. 17-089/1345). Patient data was retrieved from hospital medical record system, so an informed consent form was not required. The patient's personal data has been secured.

\section{Patient selection}

All patients enrolled were confirmed as newly diagnosed ESCC without other cancers or distant metastases between January 2002 and December 2016. The included patients met the following eligibility criteria: (I) age $\geq 18$ years old; (II) pathologically confirmed as ESCC; (III) inoperable tumor or refusing an operation; (IV) disease staging based on the sixth edition of the American Joint Committee on Cancer (AJCC 6th) tumor node metastasis (TNM) stage classification, clinical stage of TanyNanyM $M_{0}$ or $M_{1}$ with only supraclavicular or abdominal lymph node metastasis; (V) Karnofsky (KPS) score $\geq 70$; (VI) life expectancy $\geq 3$ months; (VII) initially received definitive RT of $3 \mathrm{D}$ conformal radiotherapy (3D-CRT) or IMRT.

A total of 2,762 ESCC patients were identified as the initial study population and were excluded if they met the following criteria: (I) non-SCC histology or other coexisting primary tumors; (II) prior thoracic radiotherapy or surgery; (III) radiation dose $<40$ or $>72 \mathrm{~Gy}$; (V) unconventional dose fractional RT; (V) missing clinical data.

Finally, a total of 2,469 ESCC patients treated with definitive RT were enrolled for retrospectively analysis, and were categorized into 5 groups in terms of equivalent dose in 2 Gy fractions $\left(\mathrm{EQD}_{2}\right)$ : group 1 (40 Gy $\leq \mathrm{EQD}_{2}$ $<60 \mathrm{~Gy}, \mathrm{n}=350)$, group 2 (60 Gy $\left.\leq \mathrm{EQD}_{2}<62 \mathrm{~Gy}, \mathrm{n}=1,435\right)$, group 3 (62 Gy $\left.\leq \mathrm{EQD}_{2}<64 \mathrm{~Gy}, \mathrm{n}=254\right)$, group 4 (64 Gy $\leq$ $\left.\mathrm{EQD}_{2}<66 \mathrm{~Gy}, \mathrm{n}=230\right)$ and group $5\left(66 \mathrm{~Gy} \leq \mathrm{EQD}_{2} \leq 72 \mathrm{~Gy}\right.$, $n=200$ ).

\section{Variables}

Patients received a total RT dose of 40-72 Gy (1.8-2.2 Gy/fraction). Because there was nonuniformity in the RT planning parameters collected from the different participating institutions, we used $\mathrm{EQD}_{2}$ to balance the discrepancies in RT dose-fraction among the medical centers. To evaluate the biologically effective dose (BED) in diverse dose-fractions, the linear-quadratic (LQ) model was applied to estimate equivalent radiotherapy schedules. RT doses were converted into the equivalent dose in 2 Gy fraction $\left(\mathrm{EQD}_{2}\right)$ using an $\alpha / \beta=10$ and calculated using the prescribed $\mathrm{EQD}_{2}=\mathrm{Nd}(1+\mathrm{d} / \alpha / \beta) /[1+2 / \alpha / \beta](20,21)$.

\section{Treatment and follow-up}

All patients had received radiotherapy delivered by 3DCRT or IMRT techniques. Gross tumor volume (GTV) was defined as any visible primary tumor plus metastatic lymph nodes detected by CT, esophagogram, or endoscopy. The clinical target volume (CTV) was obtained by expanding the GTV to a margin to $3.0-5.0 \mathrm{~cm}$ at the long axis and $0.8-1.0 \mathrm{~cm}$ at the lateral axis. The planning target volume (PTV) was reached by CTV plus a margin of $0.5 \mathrm{~cm}$. The planning GTV (PGTV) was reached by GTV plus a margin of $1.0 \mathrm{~cm}$. The sequential boost or simultaneous integrated boost approaches had been prescribed as the dose of 40.0-72 Gy to PGTV in 1.8-2.2 Gy fraction. Concurrent chemotherapeutic regimens were platin-based, including 5-FU-cisplatin, paclitaxel-cisplatin, and oxaliplatincapecitabine. The patients were followed up every three months during the first two years, every six months in the third and fourth years, and then on a once-yearly basis. The follow-up examinations included routine laboratory tests, neck/chest/abdomen CT scans, cervical/abdominal lymph node ultrasound, barium swallow, and/or PET/CT. If suspicious recurrent lesions were detected by imaging, biopsy was immediately applied.

\section{Statistical analysis}

The end points of this analysis were overall survival (OS), progression-free survival (PFS), local-regional failurefree survival (LRFFS), and distant metastasis-free survival (DMFS). These were defined as the time from the first treatment to the last follow-up or death by any cause, the first instance of any progression, local-regional recurrence, and tumor metastasis, respectively. The Kaplan-Meier method was used to assess the OS, PFS, LRFFS, and DMFS. Survival difference among groups with different doses was analyzed using the log-rank test. The Cox regression model was employed to perform univariate and multivariate analyses. All statistical analyses were carried out with SPSS software (version 24, IBM SPSS, CA, USA). Statistical significance was determined by a two-sided $\mathrm{P}$ value of $<0.05$.

The penalized spline (P-spline) fit in the Cox model allowed the nonlinear relationships of RT dose with the logarithm [ln hazard ratio (HR)] of mortality, disease progression, local-regional recurrence (LRR), or distant metastasis (DM), to be estimated based on the full Cox 
regression model adjusted for all covariates. P-spline was applied using the smooth HR package in $\mathrm{R}$, version 3.2.3. The dfmacox (degrees of freedom in multivariate additive Cox models) function in the smoothHR package was used to obtain the optimal number of degrees of freedom in the extended Cox-type additive multivariate analysis.

\section{Results}

\section{Patient characteristics and treatment}

A total of 2,469 patients were included in the study, of whom $65.4 \%(1,614 / 2,469)$ were less than 70 years old and $68.7 \%(1,696 / 2,469)$ were male (Table 1). According to AJCC 6th stage classification, $74.0 \%(1,828 / 2,469)$ of the patients were in stages III or IV.

In terms of treatment, $46.4 \%(1,145 / 2,469)$ patients received 3D-CRT, and $53.6 \%(1,324 / 2,469)$ patients received IMRT. CCRT was received by $43.7 \%(1,078 / 2,469)$ patients, and $17.5 \%(433 / 2,469)$ patients received adjuvant chemotherapy. RT EQD 2 was in the range of 40-72 Gy, with a median dose was $60 \mathrm{~Gy}$. The patients were further stratified into five subgroups based on the RT dose. The median follow-up time was 58.3 months [95\% confidence interval (CI): 56.4-60.2 months]. As of the date cutoff, the median OS and PFS time were 24.3 months (95\% CI: $22.5-$ 26.2 months) and 18.0 months (95\% CI: 16.4-19.6 months), respectively.

\section{Dose-dependent effect of $R T$ dose on survival}

To assess the dose-dependent effect, RT dose was entered as a continuous variable into the Cox regression using $\mathrm{P}$-splines in smoothHR to allow for the nonlinear relationships between the RT dose and end points to be identified. As shown in Figure 1, the risk (ln HR) of death decreased sharply in the range of 60 to 62 Gy, and increased slightly when dose was elevated beyond 62 Gy. Similar tendencies could been seen in the dose-dependent effect of RT for PFS, LRFFS and DMFS, though they were not as constant enough compared with OS (Figures S1-S3). These results demonstrated the dose-dependent effect of RT dose on the survival and indicated that a dose $\geq 60$ Gy was the optimal dose in treating inoperable ESCC.

\section{Univariate analyses}

The result of the univariate analysis indicated that improved
OS was closely associated with age $<70$ years old, female sex, cervical/upper esophagus location, early (I-II) AJCC clinical stage, lower T stage, node negative status, GTV volume $\leq 53 \mathrm{~cm}^{3}$, receiving IMRT, receiving CCRT or adjuvant chemoradiotherapy, and RT dose in the range of 60-62 and 62-64 Gy (Table 2).

\section{Multivariable analyses}

All factors with statistical significance in the univariate analysis were then included into the multivariate analysis. Multivariate cox regression analysis showed that age $<70$ years old, cervical/upper esophagus location, early (III) AJCC clinical stage, node negative status, GTV volume $\leq 53 \mathrm{~cm}^{3}$, receiving CCRT, and a RT dose from 60-62 Gy were still associated with better survival outcomes (Table 2). Multivariate analysis indicated that the risk of death decreased significantly (HR: $0.85,95 \%$ CI: $0.73-0.98$, $\mathrm{P}=0.028)$ in patients who received an RT dose in the range of 60-62 Gy compared with patients who received 40-60 Gy, which suggested that RT dose was an independent factor associated with OS (Table 2). Furthermore, the 60-62 Gy group also exhibited improved PFS, LRFFS, and DMFS compared with the 40-60 Gy group (PFS, HR: 0.77, 95\% CI: 0.67-0.90, $\mathrm{P}=0.001$; LRFFS, HR: 0.83, 95\% CI: 0.69-0.99, $\mathrm{P}=0.033$; DMFS, HR: $0.74,95 \%$ CI: $0.58-0.93, \mathrm{P}=0.009)$ (Tables S1-S3). Overall, RT dose was a significant independent prognostic factor for OS, PFS, LRFFS, and DMFS.

\section{Disease control and survival}

The 1-, 2-, 3- and 5-year OS rates for the entire cohort were $73.1 \%, 50.4 \%, 41.1 \%$, and $33.2 \%$, respectively; PFS was $60.3 \%, 43.4 \%, 37.0 \%$, and $32.2 \%$, respectively; LRFFS was $70.5 \%, 56.8 \%, 50.6 \%$, and $46.3 \%$, respectively; and DMFS was $84.0 \%, 75.8 \%, 73.1 \%$, and $69.7 \%$, respectively. The median OS, PFS, and LRFFS were $24.35,18.04$, and 38.28 months, respectively. In the present study, the 3 -year OS rates for the 40-60, 60-62, $62-64,64-66$, and 66-72 Gy groups were $34.6 \%, 42.0 \%$, $47.6 \%, 37.2 \%$, and $41.1 \%$, and the median OS was 19.8 , 24.1, 24.8, 30.8, 25.2, and 22.8 months, respectively. There were significant differences in $\mathrm{OS}(\mathrm{P}=0.0044$, Figure $2 A)$, PFS $(\mathrm{P}=0.0003$, Figure $2 B)$, and DMFS $(\mathrm{P}=0.0033$, Figure $3 A$ ), and a tendency toward statistical difference in LRFFS $(\mathrm{P}=0.0822$, Figure $3 B)$ among the dose groups. 
Table 1 Patient, disease, and treatment characteristics

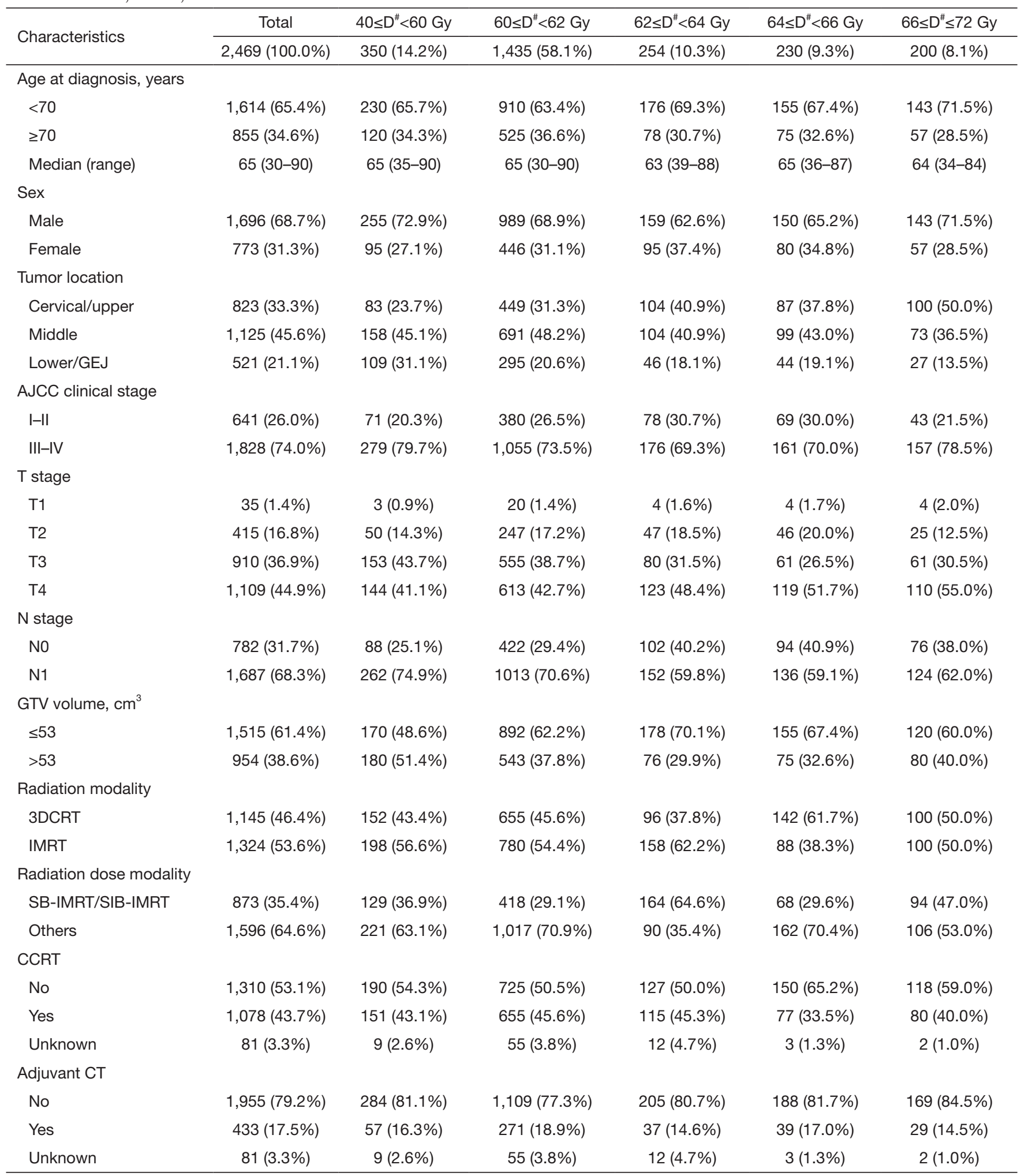

\#, equivalent dose in 2 Gy fractions $\left(\mathrm{EQD}_{2}\right)$. AJCC, American Joint Committee Cancer; GTV, gross tumor volume; 3DCRT, 3-dimensional conformal radiation therapy; IMRT, intensity modulated radiation therapy; SB-IMRT, sequential boost-IMRT; SIB-IMRT, simultaneous integrated boost-IMRT; CCRT, concurrent chemoradiotherapy; CT, chemotherapy. 


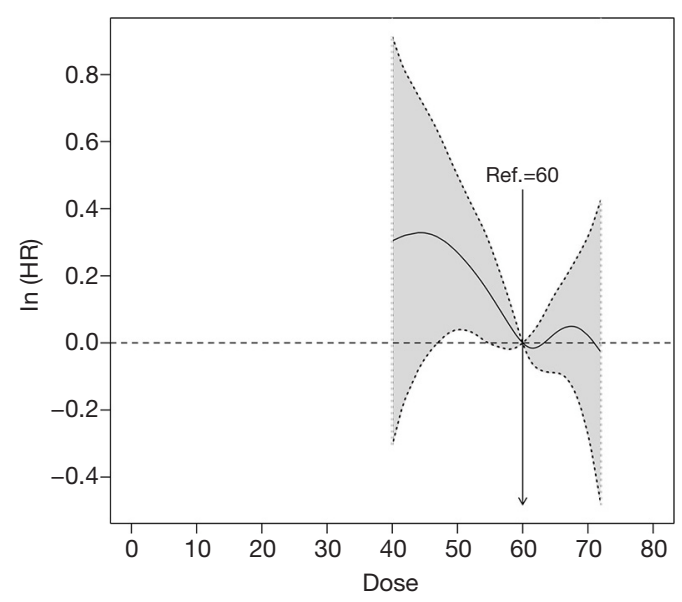

Figure 1 Estimated logarithm hazard ratios (HRs) (solid lines) with $95 \%$ confidence intervals (shading) for the association of RT dose in grays with OS. The effects of RT on the risk of mortality are modeled with a penalized spline ( $\mathrm{P}$-spline) expansion, with $\mathrm{RT}$ dose as a continuous covariate. A dose of $60 \mathrm{~Gy}$ (indicated by the vertical line), as the common cutoff value in clinical practice, was used as the reference value for calculating the HRs.

\section{Discussion}

Based on data sourced provided by 3JECROG, the association between RT dose (as a continuous covariate) and survival outcomes in ESCC was explored in this retrospective study (3JECROG R-03). RT dose was revealed to be an important prognostic factor for OS, PFS, LRFFS, and DMFS, and 60 Gy or above was the best optimal RT dose for patients who received radical radiotherapy delivered through modern RT techniques.

Our study showed that patients who received an RT dose of 60-62 Gy exhibited improved survival. However, the RTOG 9405 study demonstrated that high RT dose (64.8 Gy) was responsible for increased treatment-related mortality, and that no local control and survival benefit were observed compared with the standard dose arm (50.4 Gy) (5). The RTOG 9405 trial included patients with either SCC or adenocarcinoma, each of whom received conventional RT. The RT target varied in margin in different dose arms. Although more treatment-related deaths were observed in the high-dose arm (11 vs. 2), 7 of the 11 treatment-related

Table 2 Univariable and multivariable analysis of overall survival for all patients

\begin{tabular}{|c|c|c|c|c|c|c|}
\hline Characteristics & \multicolumn{3}{|c|}{ Univariate analysis } & \multicolumn{3}{|c|}{ Multivariate analysis } \\
\hline \multicolumn{7}{|c|}{ Age at diagnosis, years } \\
\hline$<70$ & 1.00 & - & - & 1.00 & - & - \\
\hline$\geq 70$ & 1.12 & $1.01-1.24$ & 0.029 & 1.13 & $1.01-1.26$ & 0.036 \\
\hline Female & 0.86 & $0.78-0.96$ & 0.008 & 0.93 & $0.83-1.04$ & 0.194 \\
\hline \multicolumn{7}{|l|}{ Tumor location } \\
\hline Cervical/upper & 1.00 & - & - & 1.00 & - & - \\
\hline$|-| \mid$ & 1.00 & - & - & 1.00 & - & - \\
\hline III-IV & 1.67 & $1.45-1.89$ & $<0.001$ & 1.23 & $1.01-1.49$ & 0.041 \\
\hline \multicolumn{7}{|l|}{ T stage } \\
\hline $\mathrm{T} 1$ & 1.00 & - & - & 1.00 & - & - \\
\hline $\mathrm{T} 2$ & 1.46 & $0.88-2.42$ & 0.144 & 1.31 & $0.79-2.19$ & 0.292 \\
\hline T3 & 1.73 & $1.05-2.84$ & 0.031 & 1.34 & $0.81-2.23$ & 0.260 \\
\hline $\mathrm{T} 4$ & 2.26 & $1.38-3.70$ & 0.001 & 1.54 & $0.92-2.58$ & 0.104 \\
\hline
\end{tabular}

Table 2 (continued) 
Table 2 (continued)

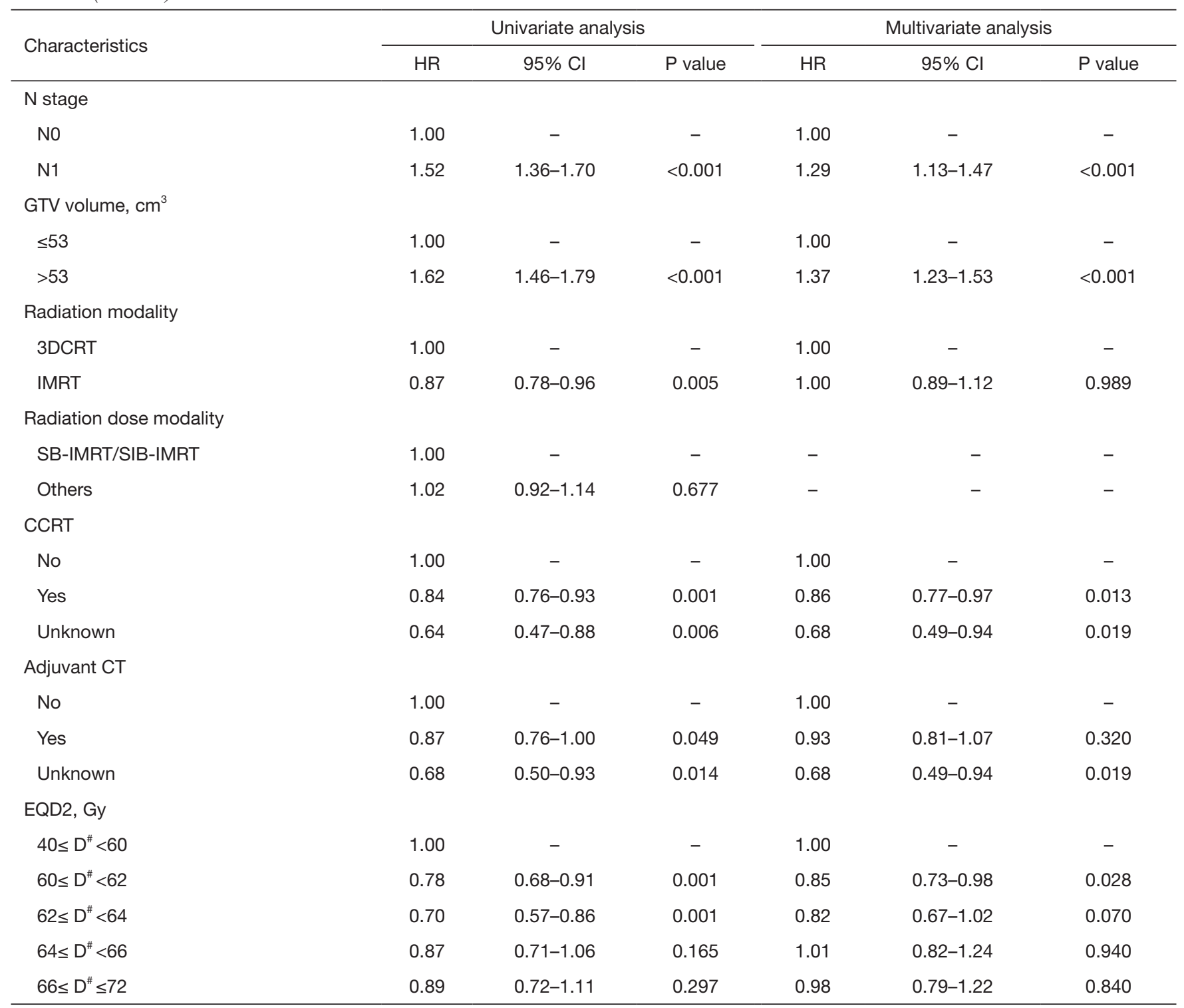

\#, equivalent dose in 2 Gy fractions $\left(E_{2}\right)$. AJCC, American Joint Committee Cancer; GTV, gross tumor volume; 3DCRT, 3-dimensional conformal radiation therapy; IMRT, intensity modulated radiation therapy; SB-IMRT, sequential boost-IMRT; SIB-IMRT, simultaneous integrated boost-IMRT; CCRT, concurrent chemoradiotherapy; CT, chemotherapy; $E Q D_{2}$, equivalent dose in 2 Gy fractions.

deaths occurred prior to a dose of 50.4 Gy being reached. In our study, we focused only on ESCC, which exhibits different biological characteristics and treatment response from adenocarcinoma. More importantly, all of the included patients were treated using modern RT techniques, including 3D-CRT and IMRT. These RT techniques dramatically reduced the incidence of toxicity because of more precise delivery RT dose to tumor and sparing the surrounding normal tissue.
A growing number of studies conducted recently have evaluated the effect of RT dose escalation on survival benefit in esophageal carcinoma by utilizing modern techniques (Table 3) $(10,12,14-16,22)$. He et al. retrospectively assessed the treatment outcomes of 3D-CRT in ESCC patients. A high RT dose (>50.4 Gy) was found to significantly improve local tumor control compared with a low RT dose ( $\leq 50.4$ Gy) (17.9\% vs. $34.3 \%, \mathrm{P}=0.024)$. However, there was no difference in five-year OS between the two groups 


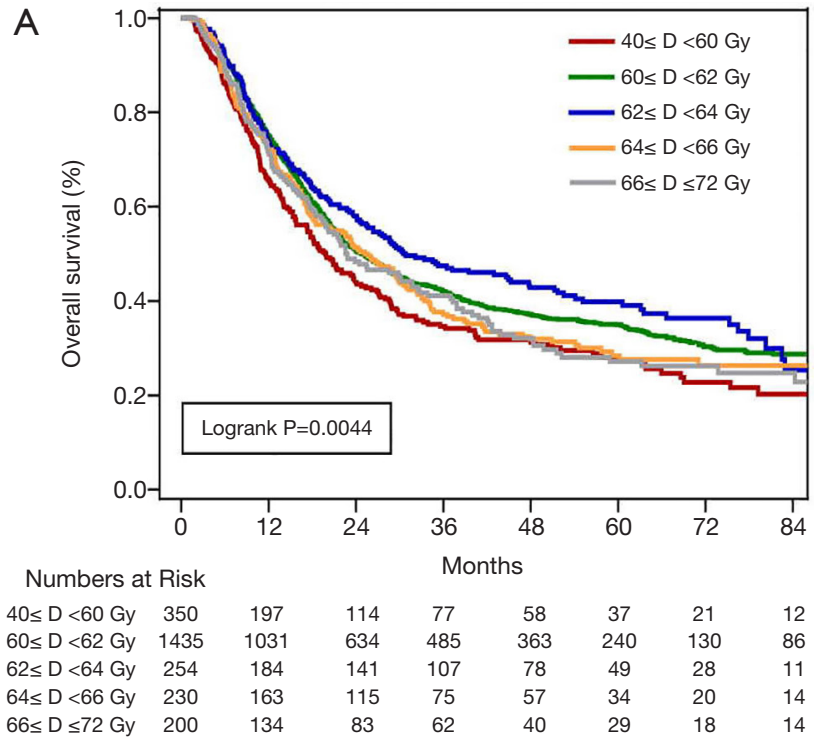

B

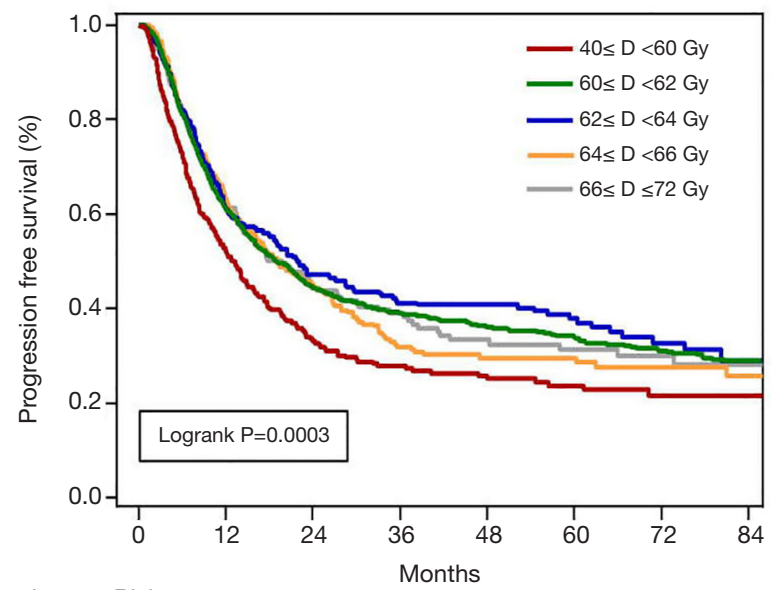

Numbers at Risk

$\begin{array}{lcccccccc}40 \leq \mathrm{D}<60 \text { Gy } & 350 & 150 & 78 & 56 & 43 & 29 & 16 & 11 \\ 60 \leq \mathrm{D}<62 \text { Gy } & 1435 & 794 & 515 & 411 & 319 & 205 & 119 & 80 \\ 62 \leq \mathrm{D}<64 \text { Gy } & 254 & 145 & 106 & 86 & 70 & 43 & 23 & 10 \\ 64 \leq \mathrm{D}<66 \text { Gy } & 230 & 141 & 97 & 61 & 47 & 32 & 20 & 13 \\ 66 \leq \mathrm{D} \leq 72 \text { Gy } & 200 & 112 & 68 & 52 & 34 & 26 & 17 & 13\end{array}$

Figure 2 Kaplan-Meier curves comparing overall survival (OS) (A) and progression-free survival (PFS) (B). By EDQ2, there were significant differences in OS $(\mathrm{P}=0.0044)$ and $\mathrm{PFS}(\mathrm{P}=0.0003)$.

$(\mathrm{P}=0.617)$ (10). Other retrospectively analyses of ESCC have also indicated that a higher RT dose results in more favorable survival outcomes (14-16). Consistently, a metaanalysis of 28 studies identified the clinical outcomes between high RT dose ( $\geq 60 \mathrm{~Gy}$ ) and the conventional dose. The results suggested that CCRT with a high dose improved clinical outcomes compared with the conventional dose, especially in ESCC (17). As modern RT techniques were used in all studies mentioned above,
A

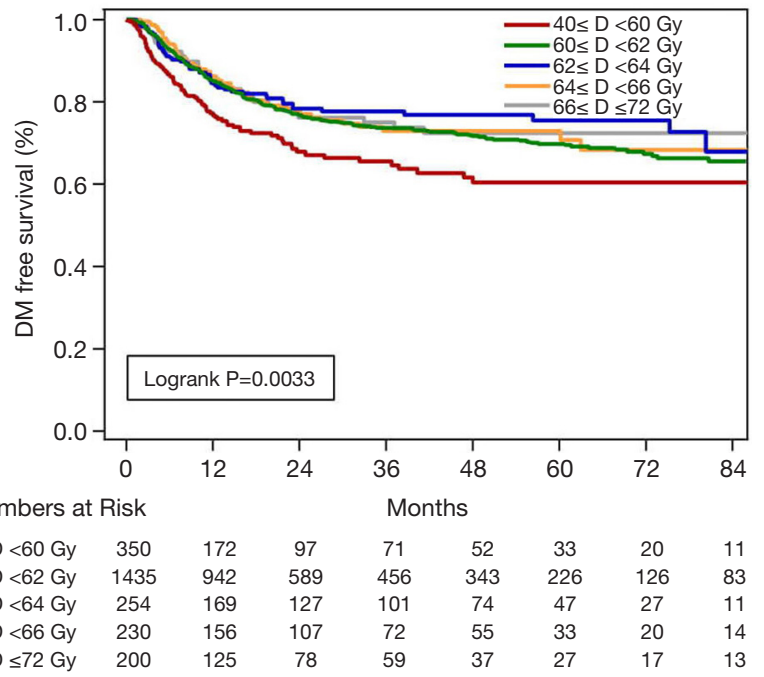

B

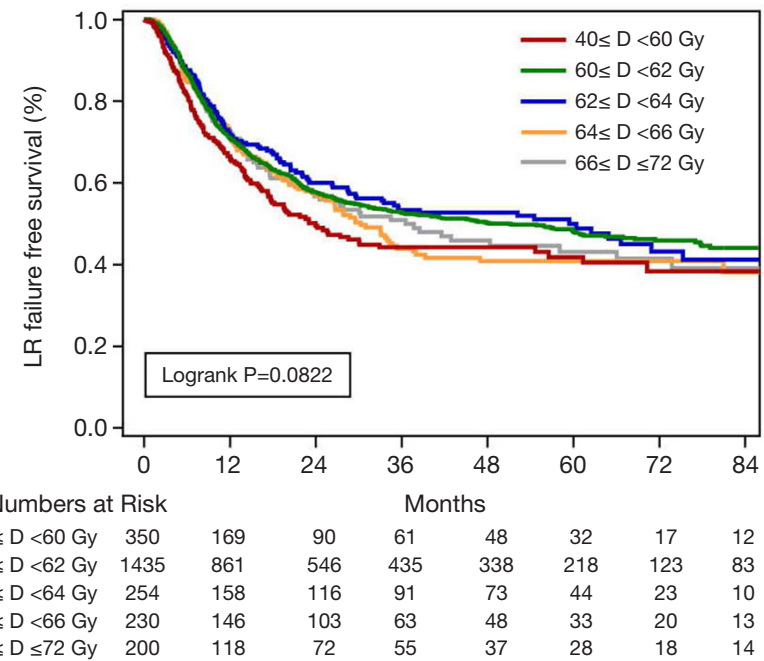

Figure 3 Kaplan-Meier curves comparing distant metastasis-free survival (A) and local-regional failure-free survival (B). By EDQ2, there were a tendency toward difference in (DMFS) $(\mathrm{P}=0.0033)$ and significant differences in distant metastasis-free survival LRFFS ( $\mathrm{P}=0.0822)$.

treatment-related toxicity reached an acceptable level and no treatment-related deaths occurred. The survival rate in the high dose group was also increased with the use of $3 \mathrm{D}$-CRT or IMRT compared with the use of 2D-RT (23). However, Ren et al. noted that an RT dose above 60 Gy significantly increased the incidence of conditions such as severe radiation esophagitis, radiation pneumonitis, hemorrhage, and fistula (16). The findings of this present multi-center respective study 
Table 3 Studies regarding high-dose and conventional-dose radiotherapy for patients with esophageal carcinoma utilizing modern techniques

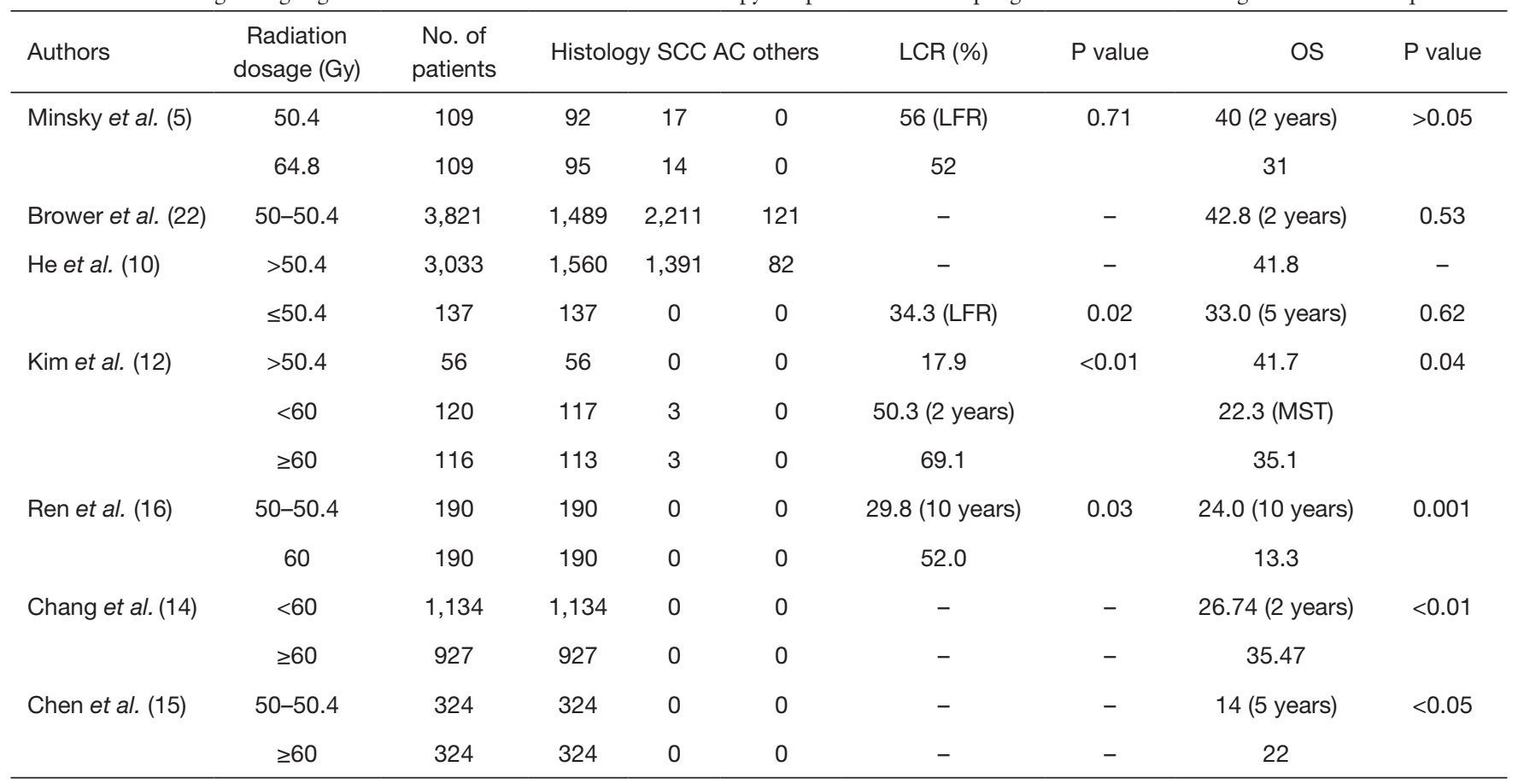

SCC, squamous cell carcinoma; AC, adenocarcinoma; LCR, local control rate; LFR, local failure rate; OS, overall survival; MST, median survival time.

support those of previous studies. Improved survival was found when RT dose was raised above $60 \mathrm{~Gy}$. When the RT dose exceeded 64 Gy, the OS rate decreased. Treatmentrelated toxicity was most likely one of the most important factors leading to worse survival.

Despite radical radiotherapy treatment, owing to the high local recurrence rate, patients with locally advanced esophageal cancer usually have a poor prognosis $(5,6)$. The LRR rate of ESCC is higher than that of esophageal adenocarcinoma $(24,25)$. Several studies have verified that RT dose escalation benefits the local control rates, especially in ESCC (12,26-31). Zhang et al. investigated 69 patients with stage II-III unresectable esophageal cancer treated with CCRT. The patients in the high RT dose ( $>51 \mathrm{~Gy}$ ) group had better 3-year local control rate (36\% vs. 19\%) and DFS ( $25 \%$ vs. $10 \%$ ) than those in the low RT dose ( $\leq 51 \mathrm{~Gy})$ group, although the OS was not significantly different between these two groups ( $13 \%$ vs. $3 \%, \mathrm{P}=0.054)$ (26). Kim et al. found that patients in the high RT dose ( $\geq 60$ Gy) group had significantly better 2-year LRC (69.1\% vs. $50.3 \%, \mathrm{P}=0.002)$, median PFS (16.7 vs. 11.7 months, $\mathrm{P}=0.029)$, and median $\mathrm{OS}$ (35.1 vs. 22.3 months, $\mathrm{P}=0.043$ ) than the low RT dose group (12). Furthermore, RT doses of at least 60 Gy have been reported to improve OS and locoregional control, especially in Asian countries (32). A high RT dose ( $\geq 60 \mathrm{~Gy}$ ) was recommended for locally advanced esophageal cancer in several Asian countries $(33,34)$. These previous studies support our findings that RT $\geq 60$ Gy exhibits better local control and OS benefits than RT dose $<60$ Gy.

There were some limitations to our analysis owing to the retrospective nature of this database cohort study. Firstly, a selection bias in various RT dose subgroups and chemotherapy regimens may have existed. Secondly, as half of the patients were stratified in the 60-62 Gy group, generalizability in the data analysis might have been affected. Thirdly, the RT biological effect on survival might have been affected by inconsistent fraction dose, dose rate, and overall treatment time (35). In the present study, we used $\mathrm{EQD}_{2}$ to estimate equivalent $\mathrm{RT}$ schedules in various institutions. Larger-scale, prospective, randomized trials are needed to confirm our results. Currently, there are two ongoing Chinese clinical trials to compare high-dose RT (60-61.2 Gy) with the standard-dose (50-50.4 Gy) for the treatment of inoperable EC patients receiving CCRT using IMRT. 


\section{Conclusions}

In conclusion, our results suggest RT dose to be a significant prognostic factor for survival in patients with locally advanced ESCC. Within a certain RT dose, higher RT dose yields more favorable survival outcomes for ESCC patients treated with definitive RT using modern techniques, and 60 Gy or above was the optimal RT dose.

\section{Acknowledgments}

Funding: This study was supported by the National Nature Science Foundation of China (81872462); and the Clinical Trial Supporting Foundation of Tianjin Medical University Cancer Institute \& Hospital (Grant No.C1707).

\section{Footnote}

Reporting Checklist: The authors have completed the STROBE reporting checklist. Available at http://dx.doi. org/10.21037/atm-20-4672

Data Sharing Statement: Available at http://dx.doi. org/10.21037/atm-20-4672

Conflicts of Interest: All authors have completed the ICMJE uniform disclosure form (available at http://dx.doi. org/10.21037/atm-20-4672). The authors have no conflicts of interest to declare.

Ethical Statement: The authors are accountable for all aspects of the work in ensuring that questions related to the accuracy or integrity of any part of the work are appropriately investigated and resolved. All procedures performed in this study involving human participants were in accordance with the Declaration of Helsinki (as revised in 2013). The study was approved by the Ethics Committee of National Cancer Center/Cancer Hospital, Chinese Academy of Medical Sciences and Peking Union Medical College (No. 17-089/1345). Patient data was retrieved from hospital medical record system, so an informed consent form was not required. The patient's personal data has been secured.

Open Access Statement: This is an Open Access article distributed in accordance with the Creative Commons Attribution-NonCommercial-NoDerivs 4.0 International License (CC BY-NC-ND 4.0), which permits the non- commercial replication and distribution of the article with the strict proviso that no changes or edits are made and the original work is properly cited (including links to both the formal publication through the relevant DOI and the license). See: https://creativecommons.org/licenses/by-nc-nd/4.0/.

\section{References}

1. Bray F, Ferlay J, Soerjomataram I, et al. Global cancer statistics 2018: GLOBOCAN estimates of incidence and mortality worldwide for 36 cancers in 185 countries. CA Cancer J Clin 2018;68:394-424.

2. Shapiro J, van Lanschot JJB, Hulshof M, et al. Neoadjuvant chemoradiotherapy plus surgery versus surgery alone for oesophageal or junctional cancer (CROSS): long-term results of a randomised controlled trial. Lancet Oncol 2015;16:1090-8.

3. Yang H, Liu H, Chen Y, et al. Neoadjuvant Chemoradiotherapy Followed by Surgery Versus Surgery Alone for Locally Advanced Squamous Cell Carcinoma of the Esophagus (NEOCRTEC5010): A Phase III Multicenter, Randomized, Open-Label Clinical Trial. J Clin Oncol 2018;36:2796-803.

4. Cooper JS, Guo MD, Herskovic A, et al. Chemoradiotherapy of locally advanced esophageal cancer: long-term follow-up of a prospective randomized trial (RTOG 85-01). Radiation Therapy Oncology Group. JAMA 1999;281:1623-7.

5. Minsky BD, Pajak TF, Ginsberg RJ, et al. INT 0123 (Radiation Therapy Oncology Group 94-05) phase III trial of combined-modality therapy for esophageal cancer: high-dose versus standard-dose radiation therapy. J Clin Oncol 2002;20:1167-74.

6. Welsh J, Settle SH, Amini A, et al. Failure patterns in patients with esophageal cancer treated with definitive chemoradiation. Cancer 2012;118:2632-40.

7. Xi M, Xu C, Liao Z, et al. The impact of histology on recurrence patterns in esophageal cancer treated with definitive chemoradiotherapy. Radiother Oncol 2017;124:318-24.

8. Tu CC, Hsu PK. The frontline of esophageal cancer treatment: questions to be asked and answered. Ann Transl Med 2018;6:83.

9. Ma WJ, Zhang QN, Shi SZ, et al. Preoperative chemoradiation may be more effective for esophageal squamous cell carcinoma compared with adenocarcinoma: results from 15 randomized controlled trials of 2,250 patients. Transl Cancer Res 2018;7:1421-30. 
10. He L, Allen PK, Potter A, et al. Re-evaluating the optimal radiation dose for definitive chemoradiotherapy for esophageal squamous cell carcinoma. J Thorac Oncol 2014;9:1398-405.

11. Higuchi K, Komori S, Tanabe S, et al. Definitive chemoradiation therapy with docetaxel, cisplatin, and 5-fluorouracil (DCF-R) in advanced esophageal cancer: a phase 2 trial (KDOG 0501-P2). Int J Radiat Oncol Biol Phys 2014;89:872-9.

12. Kim HJ, Suh YG, Lee YC, et al. Dose-Response Relationship between Radiation Dose and Loco-regional Control in Patients with Stage II-III Esophageal Cancer Treated with Definitive Chemoradiotherapy. Cancer Res Treat 2017;49:669-77.

13. Clavier JB, Antoni D, Atlani D, et al. Definitive chemoradiotherapy for esophageal cancer: 66Gy versus 50Gy, a retrospective study. Cancer Radiother 2013;17:221-8.

14. Chang CL, Tsai HC, Lin WC, et al. Dose escalation intensity-modulated radiotherapy-based concurrent chemoradiotherapy is effective for advanced-stage thoracic esophageal squamous cell carcinoma. Radiother Oncol 2017;125:73-9.

15. Chen CY, Li CC, Chien CR. Does higher radiation dose lead to better outcome for non-operated localized esophageal squamous cell carcinoma patients who received concurrent chemoradiotherapy? A population based propensity-score matched analysis. Radiother Oncol 2016;120:136-9.

16. Ren X, Wang L, Han C, et al. Retrospective analysis of safety profile of high-dose concurrent chemoradiotherapy for patients with oesophageal squamous cell carcinoma. Radiother Oncol 2018;129:293-9.

17. Song T, Liang X, Fang M, et al. High-dose versus conventional-dose irradiation in cisplatin-based definitive concurrent chemoradiotherapy for esophageal cancer: a systematic review and pooled analysis. Expert Rev Anticancer Ther 2015;15:1157-69.

18. Nicolini G, Ghosh-Laskar S, Shrivastava SK, et al. Volumetric modulation arc radiotherapy with flattening filter-free beams compared with static gantry IMRT and 3D conformal radiotherapy for advanced esophageal cancer: a feasibility study. Int J Radiat Oncol Biol Phys 2012;84:553-60.

19. Yaremko BP, Palma DA, Erickson AL, et al. Adjuvant concurrent chemoradiation using intensity-modulated radiotherapy and simultaneous integrated boost for resected high-risk adenocarcinoma of the distal esophagus and gastro-esophageal junction. Radiat Oncol 2013;8:33.

20. Dale RG. The application of the linear-quadratic doseeffect equation to fractionated and protracted radiotherapy. Br J Radiol 1985;58:515-28.

21. Bentzen SM, Dörr W, Gahbauer R, et al. Bioeffect modeling and equieffective dose concepts in radiation oncology--terminology, quantities and units. Radiother Oncol 2012;105:266-8.

22. Brower JV, Chen S, Bassetti MF, et al. Radiation Dose Escalation in Esophageal Cancer Revisited: A Contemporary Analysis of the National Cancer Data Base, 2004 to 2012. Int J Radiat Oncol Biol Phys 2016;96:985-93.

23. Luo Y, Mao Q, Wang X, et al. Radiotherapy for esophageal carcinoma: dose, response and survival. Cancer Manag Res 2017; 10:13-21.

24. Lieberman MD, Shriver CD, Bleckner S, et al. Carcinoma of the esophagus. Prognostic significance of histologic type. J Thorac Cardiovasc Surg 1995;109:130-8; discussion 139.

25. Siewert JR, Ott K. Are squamous and adenocarcinomas of the esophagus the same disease? Semin Radiat Oncol 2007;17:38-44.

26. Zhang Z, Liao Z, Jin J, et al. Dose-response relationship in locoregional control for patients with stage II-III esophageal cancer treated with concurrent chemotherapy and radiotherapy. Int J Radiat Oncol Biol Phys 2005;61:656-64.

27. Suh YG, Lee IJ, Koom WS, et al. High-dose versus standard-dose radiotherapy with concurrent chemotherapy in stages II-III esophageal cancer. Jpn J Clin Oncol 2014;44:534-40.

28. Gemici C, Yaprak G, Batirel HF, et al. Radiation field size and dose determine oncologic outcome in esophageal cancer. World J Surg Oncol 2016;14:263.

29. Yu WW, Zhu ZF, Fu XL, et al. Simultaneous integrated boost intensity-modulated radiotherapy in esophageal carcinoma: early results of a phase II study. Strahlenther Onkol 2014;190:979-86.

30. Chen J, Guo H, Zhai T, et al. Radiation dose escalation by simultaneous modulated accelerated radiotherapy combined with chemotherapy for esophageal cancer: a phase II study. Oncotarget 2016;7:22711-9.

31. Welsh JW, Seyedin SN, Allen PK, et al. Local Control and Toxicity of a Simultaneous Integrated Boost for Dose Escalation in Locally Advanced Esophageal Cancer: Interim Results from a Prospective Phase I/II Trial. J Thorac Oncol 2017;12:375-82.

32. Chen Y, Zhu HP, Wang T, et al. What is the optimal radiation dose for non-operable esophageal cancer? 
Page 12 of 12

Dissecting the evidence in a meta-analysis. Oncotarget 2017;8:89095-107.

33. Chen Y, Ye J, Zhu Z, et al. Comparing Paclitaxel Plus Fluorouracil Versus Cisplatin Plus Fluorouracil in Chemoradiotherapy for Locally Advanced Esophageal Squamous Cell Cancer: A Randomized, Multicenter, Phase
Zhang et al. Dose escalation of 3DRT is effective for ESCC

III Clinical Trial. J Clin Oncol 2019;37:1695-703.

34. Kitagawa Y, Uno T, Oyama T, et al. Esophageal cancer practice guidelines 2017 edited by the Japan esophageal society: part 2. Esophagus 2019;16:25-43.

35. Fletcher GH. Regaud lecture perspectives on the history of radiotherapy. Radiother Oncol 1988;12:iii-v, 253-71.

Cite this article as: Zhang W, Zhao J, Han W, Zhang $\mathrm{H}$, Wang X, Li C, Chen J, Wang X, Zhao Y, Qiao X, Zhou Z, Han C, Zhu S, Shen W, Wang L, Ge X, Sun X, Zhang K, Hu M, Li L, Hao C, Li G, Xu Y, Wang Y, Lu N, Liu M, Qian S, Xiao Z, Wang P, Pang Q. Dose escalation of 3D radiotherapy is effective for esophageal squamous cell carcinoma: a multicenter retrospective analysis (3JECROG R-03). Ann Transl Med 2020;8(18):1140. doi: 10.21037/atm-20-4672 


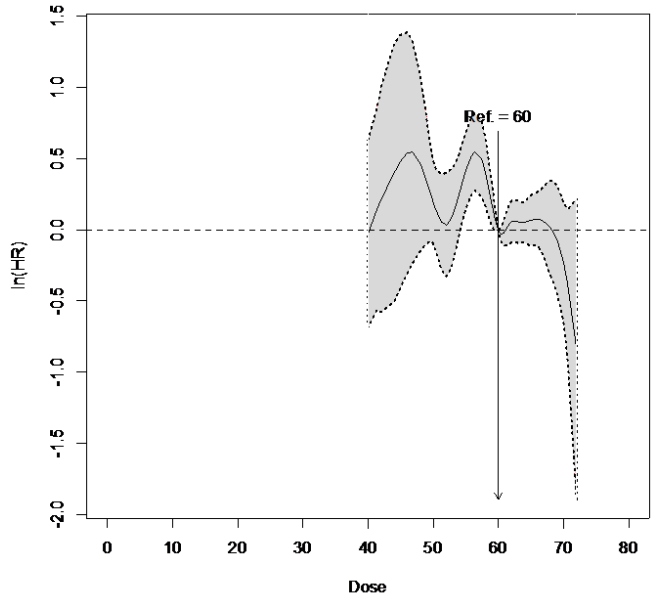

Figure S1 Dose-dependent effect of radiotherapy on progressionfree survival.

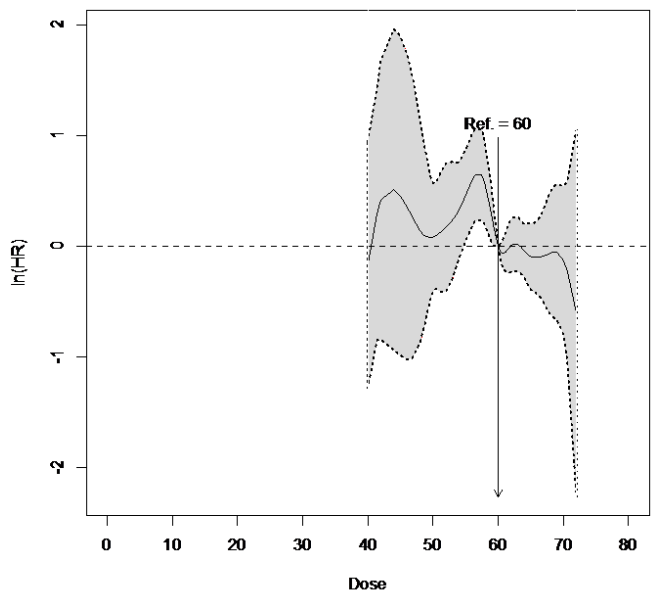

Figure S2 Dose-dependent effect of radiotherapy on distant metastasis.

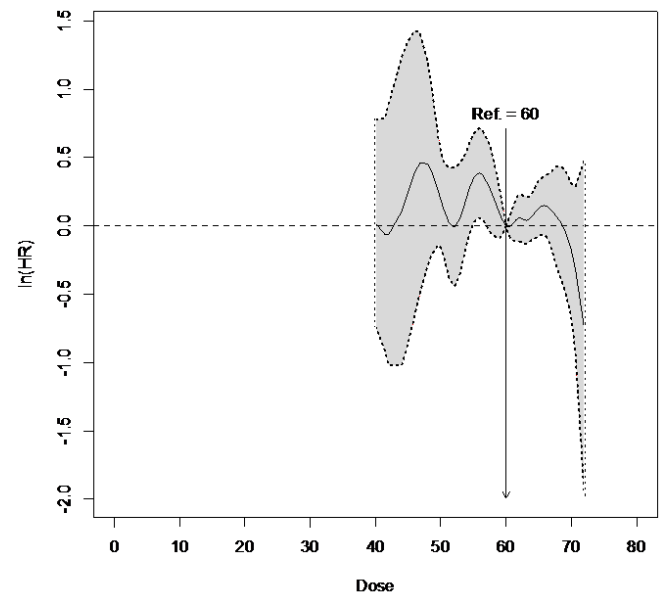

Figure S3 Dose-dependent effect of radiotherapy on localregional control. 
Table S1 Univariable and multivariable analysis of progression-free survival for all patients

\begin{tabular}{|c|c|c|c|c|c|c|}
\hline \multirow{2}{*}{ Characteristics } & \multicolumn{3}{|c|}{ Univariate analysis } & \multicolumn{3}{|c|}{ Multivariate analysis } \\
\hline & HR & $95 \% \mathrm{Cl}$ & $P$ value & $\mathrm{HR}$ & $95 \% \mathrm{Cl}$ & $P$ value \\
\hline \multicolumn{7}{|l|}{ Age at diagnosis, years } \\
\hline$<70$ & 1.00 & & & - & - & - \\
\hline$\geq 70$ & 1.05 & $0.94-1.16$ & 0.398 & - & - & - \\
\hline Sex & & & & - & - & - \\
\hline Male & 1.00 & & & 1.00 & & \\
\hline Female & 0.84 & $0.76-0.94$ & 0.002 & 0.91 & $0.81-1.02$ & 0.088 \\
\hline \multicolumn{7}{|l|}{ Tumor location } \\
\hline Cervical/upper & 1.00 & & & 1.00 & & \\
\hline Middle & 1.27 & $1.13-1.43$ & $<0.001$ & 1.19 & $1.06-1.34$ & 0.003 \\
\hline Lower/GEJ & 1.27 & $1.11-1.46$ & 0.001 & 1.19 & $1.03-1.37$ & 0.021 \\
\hline \multicolumn{7}{|l|}{ AJCC clinical stage } \\
\hline I-II & 1.00 & & & 1.00 & & \\
\hline III-IV & 1.63 & $1.44-1.84$ & $<0.001$ & 1.19 & $0.98-1.45$ & 0.081 \\
\hline \multicolumn{7}{|l|}{ T Stage } \\
\hline $\mathrm{T} 1$ & 1.00 & & & 1.00 & & \\
\hline $\mathrm{T} 2$ & 1.42 & $0.84-2.40$ & 0.188 & 1.23 & $0.73-2.09$ & 0.431 \\
\hline T3 & 1.85 & $1.11-3.10$ & 0.018 & 1.38 & $0.82-2.34$ & 0.229 \\
\hline $\mathrm{T} 4$ & 2.19 & $1.31-3.65$ & 0.003 & 1.48 & $0.87-2.54$ & 0.151 \\
\hline \multicolumn{7}{|l|}{ N Stage } \\
\hline NO & 1.00 & & & 1.00 & & \\
\hline $\mathrm{N} 1$ & 1.50 & $1.34-1.68$ & $<0.001$ & 1.28 & $1.11-1.46$ & $<0.001$ \\
\hline \multicolumn{7}{|l|}{ GTV volume, $\mathrm{cm}^{3}$} \\
\hline$\leq 53$ & 1.00 & & & 1.00 & & \\
\hline$>53$ & 1.52 & $1.38-1.69$ & $<0.001$ & 1.30 & $1.16-1.45$ & $<0.001$ \\
\hline \multicolumn{7}{|l|}{ Radiation modality } \\
\hline 3DCRT & 1.00 & & & - & - & - \\
\hline IMRT & 1.00 & $0.90-1.10$ & 0.925 & - & - & - \\
\hline \multicolumn{7}{|l|}{ Radiation dose modality } \\
\hline SB-IMRT/SIB-IMRT & 1.00 & & & - & - & - \\
\hline Others & 0.96 & $0.86-1.07$ & 0.474 & - & - & - \\
\hline \multicolumn{7}{|l|}{ CCRT } \\
\hline No & 1.00 & & & - & - & - \\
\hline Yes & 1.00 & $0.90-1.11$ & 0.962 & - & - & - \\
\hline Unknown & 1.10 & $0.83-1.46$ & 0.502 & - & - & - \\
\hline \multicolumn{7}{|l|}{ Adjuvant CT } \\
\hline No & 1.00 & & & - & - & - \\
\hline Yes & 0.99 & $0.87-1.13$ & 0.887 & - & - & - \\
\hline Unknown & 1.10 & $0.83-1.45$ & 0.501 & - & - & - \\
\hline \multicolumn{7}{|l|}{ EQD2, Gy } \\
\hline $40 \leq \mathrm{D}<60$ & 1.00 & & & 1.00 & & \\
\hline $60 \leq \mathrm{D}<62$ & 0.73 & $0.63-0.84$ & $<0.001$ & 0.77 & $0.67-0.90$ & 0.001 \\
\hline $62 \leq \mathrm{D}<64$ & 0.68 & $0.55-0.83$ & $<0.001$ & 0.78 & $0.63-0.96$ & 0.018 \\
\hline $64 \leq \mathrm{D}<66$ & 0.77 & $0.63-0.94$ & 0.012 & 0.88 & $0.72-1.09$ & 0.236 \\
\hline $66 \leq \mathrm{D} \leq 72$ & 0.74 & $0.59-0.92$ & 0.007 & 0.80 & $0.64-1.00$ & 0.053 \\
\hline
\end{tabular}

AJCC, American Joint Committee Cancer; GTV, gross tumor volume; 3DCRT, 3-dimensional conformal radiation therapy; IMRT, intensity modulated radiation therapy; SB-IMRT, sequential boost-IMRT; SIB-IMRT, simultaneous integrated boost-IMRT; CCRT, concurrent chemoradiotherapy; $\mathrm{CT}$, chemotherapy; $\mathrm{EQD}_{2}$, equivalent dose in 2 Gy fractions. 
Table S2 Univariable and multivariable analysis of local-regional failure-free survival for all patients

\begin{tabular}{|c|c|c|c|c|c|c|}
\hline \multirow{2}{*}{ Characteristics } & \multicolumn{3}{|c|}{ Univariate analysis } & \multicolumn{3}{|c|}{ Multivariate analysis } \\
\hline & $\mathrm{HR}$ & $95 \% \mathrm{Cl}$ & $P$ value & $\mathrm{HR}$ & $95 \% \mathrm{Cl}$ & $P$ value \\
\hline \multicolumn{7}{|l|}{ Age at diagnosis, years } \\
\hline$<70$ & 1.00 & & & - & - & - \\
\hline$\geq 70$ & 1.07 & $0.95-1.21$ & 0.256 & - & - & - \\
\hline \multicolumn{7}{|l|}{ Sex } \\
\hline Male & 1.00 & & & - & - & - \\
\hline Female & 0.93 & $0.82-1.05$ & 0.229 & - & - & - \\
\hline \multicolumn{7}{|l|}{ Tumor location } \\
\hline Cervical/upper & 1.00 & & & 1.00 & & \\
\hline Middle & 1.23 & $1.08-1.41$ & 0.002 & 1.19 & $1.04-1.37$ & 0.012 \\
\hline Lower/GEJ & 1.11 & $0.94-1.31$ & 0.230 & 1.07 & $0.90-1.27$ & 0.478 \\
\hline \multicolumn{7}{|l|}{ AJCC clinical stage } \\
\hline I-II & 1.00 & & & 1.00 & & \\
\hline III-IV & 1.40 & $1.22-1.62$ & $<0.001$ & 1.09 & $0.87-1.37$ & 0.451 \\
\hline \multicolumn{7}{|l|}{ T stage } \\
\hline $\mathrm{T} 1$ & 1.00 & & & 1.00 & & \\
\hline $\mathrm{T} 2$ & 1.10 & $0.64-1.90$ & 0.732 & 1.00 & $0.58-1.73$ & 0.996 \\
\hline T3 & 1.36 & $0.80-2.32$ & 0.258 & 1.14 & $0.66-1.98$ & 0.637 \\
\hline $\mathrm{T} 4$ & 1.57 & $0.92-2.66$ & 0.098 & 1.22 & $0.69-2.14$ & 0.495 \\
\hline \multicolumn{7}{|l|}{$\mathrm{N}$ stage } \\
\hline No & 1.00 & & & 1.00 & & \\
\hline $\mathrm{N} 1$ & 1.29 & $1.13-1.47$ & $<0.001$ & 1.16 & $0.99-1.35$ & 0.074 \\
\hline \multicolumn{7}{|l|}{ GTV volume, $\mathrm{cm}^{3}$} \\
\hline$\leq 53$ & 1.00 & & & 1.00 & & \\
\hline$>53$ & 1.38 & $1.23-1.56$ & $<0.001$ & 1.25 & $1.10-1.43$ & 0.001 \\
\hline \multicolumn{7}{|l|}{ Radiation modality } \\
\hline 3DCRT & 1.00 & & & - & - & - \\
\hline IMRT & 0.90 & $0.88-1.11$ & 0.856 & - & - & - \\
\hline \multicolumn{7}{|l|}{ Radiation dose modality } \\
\hline SB-IMRT/SIB-IMRT & 1.00 & & & - & - & - \\
\hline Others & 0.95 & $0.84-1.08$ & 0.462 & - & - & - \\
\hline \multicolumn{7}{|l|}{ CCRT } \\
\hline No & 1.00 & & & & & \\
\hline Yes & 0.94 & $0.83-1.06$ & 0.302 & - & - & - \\
\hline Unknown & 1.11 & $0.81-1.53$ & 0.528 & - & - & - \\
\hline \multicolumn{7}{|l|}{ Adjuvant CT } \\
\hline No & 1.00 & & & - & - & - \\
\hline Yes & 1.06 & $0.91-1.24$ & 0.443 & - & - & - \\
\hline Unknown & 1.15 & $0.84-1.58$ & 0.381 & - & - & - \\
\hline \multicolumn{7}{|l|}{ EQD2, Gy } \\
\hline $40 \leq \mathrm{D}<60$ & 1.00 & & & 1.00 & & \\
\hline $60 \leq \mathrm{D}<62$ & 0.79 & $0.66-0.94$ & 0.009 & 0.83 & $0.69-0.99$ & 0.033 \\
\hline $62 \leq \mathrm{D}<64$ & 0.76 & $0.60-0.97$ & 0.027 & 0.84 & $0.66-1.07$ & 0.154 \\
\hline $64 \leq \mathrm{D}<66$ & 0.89 & $0.70-1.13$ & 0.319 & 0.98 & $0.77-1.17$ & 0.864 \\
\hline $66 \leq \mathrm{D} \leq 72$ & 0.85 & $0.66-1.10$ & 0.226 & 0.91 & $0.45-1.13$ & 0.454 \\
\hline
\end{tabular}

AJCC, American Joint Committee Cancer; GTV, gross tumor volume; 3DCRT, 3-dimensional conformal radiation therapy; IMRT, intensity modulated radiation therapy; SB-IMRT, sequential boost-IMRT; SIB-IMRT, simultaneous integrated boost-IMRT; CCRT, concurrent chemoradiotherapy; $\mathrm{CT}$, chemotherapy; $\mathrm{EQD}_{2}$, equivalent dose in 2 Gy fractions. 
Table S3 Univariable and multivariable analysis of distant metastasis-free survival for all patients

\begin{tabular}{|c|c|c|c|c|c|c|}
\hline \multirow{2}{*}{ Characteristics } & \multicolumn{3}{|c|}{ Univariate analysis } & \multicolumn{3}{|c|}{ Multivariate analysis } \\
\hline & $\mathrm{HR}$ & $95 \% \mathrm{Cl}$ & $P$ value & $\mathrm{HR}$ & $95 \% \mathrm{Cl}$ & $P$ value \\
\hline \multicolumn{7}{|l|}{ Age at diagnosis, years } \\
\hline$<70$ & 1.00 & & & - & - & - \\
\hline$\geq 70$ & 0.95 & $0.80-1.14$ & 0.589 & - & - & - \\
\hline \multicolumn{7}{|l|}{ Sex } \\
\hline Male & 1.00 & & & 1.00 & & \\
\hline Female & 0.80 & $0.66-0.96$ & 0.014 & 0.87 & $0.72-1.05$ & 0.153 \\
\hline \multicolumn{7}{|l|}{ Tumor location } \\
\hline Cervical/upper & 1.00 & & & 1.00 & & \\
\hline Middle & 1.35 & $1.11-1.64$ & 0.003 & 1.22 & $1.00-1.49$ & 0.050 \\
\hline Lower/GEJ & 1.53 & $1.22-1.92$ & $<0.001$ & 1.41 & $1.11-1.79$ & 0.005 \\
\hline \multicolumn{7}{|l|}{ AJCC clinical stage } \\
\hline I-II & 1.00 & & & 1.00 & & \\
\hline III-IV & 2.36 & $1.88-2.97$ & $<0.001$ & 1.65 & $1.16-2.33$ & 0.005 \\
\hline \multicolumn{7}{|l|}{ T stage } \\
\hline $\mathrm{T} 1$ & 1.00 & & & 1.00 & & \\
\hline $\mathrm{T} 2$ & 3.45 & $0.85-14.06$ & 0.084 & 2.81 & $0.69-11.49$ & 0.150 \\
\hline T3 & 5.09 & $1.26-20.47$ & 0.022 & 2.76 & $0.68-11.29$ & 0.157 \\
\hline $\mathrm{T} 4$ & 6.10 & $1.52-24.52$ & 0.011 & 2.96 & $0.72-12.18$ & 0.133 \\
\hline \multicolumn{7}{|l|}{$\mathrm{N}$ stage } \\
\hline No & 1.00 & & & 1.00 & & \\
\hline $\mathrm{N} 1$ & 2.10 & $1.71-2.57$ & $<0.001$ & 1.57 & $1.24-2.00$ & $<0.001$ \\
\hline \multicolumn{7}{|l|}{ GTV volume, $\mathrm{cm}^{3}$} \\
\hline$\leq 53$ & 1.00 & & & 1.00 & & \\
\hline$>53$ & 1.71 & $1.45-2.02$ & $<0.001$ & 1.32 & $1.11-1.58$ & 0.002 \\
\hline \multicolumn{7}{|l|}{ Radiation modality } \\
\hline 3DCRT & 1.00 & & & - & - & - \\
\hline IMRT & 0.95 & $0.81-1.13$ & 0.565 & - & - & - \\
\hline \multicolumn{7}{|l|}{ Radiation dose modality } \\
\hline SB-IMRT/SIB-IMRT & 1.00 & & & - & - & - \\
\hline Others & 1.06 & $0.89-1.26$ & 0.537 & - & - & - \\
\hline \multicolumn{7}{|l|}{ CCRT } \\
\hline No & 1.00 & & & - & - & - \\
\hline Yes & 1.02 & $0.86-1.21$ & 0.816 & - & - & - \\
\hline Unknown & 1.33 & $0.88-2.01$ & 0.182 & - & - & - \\
\hline \multicolumn{7}{|l|}{ Adjuvant CT } \\
\hline No & 1.00 & & & 1.00 & & \\
\hline Yes & 0.83 & $0.66-1.05$ & 0.119 & 0.82 & $0.65-1.03$ & 0.094 \\
\hline Unknown & 1.28 & $0.85-1.92$ & 0.247 & 1.53 & $1.01-2.32$ & 0.045 \\
\hline \multicolumn{7}{|l|}{ EQD2, Gy } \\
\hline $40 \leq \mathrm{D}<60$ & 1.00 & & & & & \\
\hline $60 \leq \mathrm{D}<62$ & 0.67 & $0.53-0.84$ & 0.001 & 0.74 & $0.58-0.93$ & 0.009 \\
\hline $62 \leq \mathrm{D}<64$ & 0.59 & $0.42-0.82$ & 0.002 & 0.72 & $0.51-1.01$ & 0.056 \\
\hline $64 \leq \mathrm{D}<66$ & 0.63 & $0.45-0.88$ & 0.008 & 0.78 & $0.55-1.10$ & 0.151 \\
\hline $66 \leq \mathrm{D} \leq 72$ & 0.62 & $0.43-0.89$ & 0.010 & 0.72 & $0.49-1.04$ & 0.080 \\
\hline
\end{tabular}

AJCC, American Joint Committee Cancer; GTV, gross tumor volume; 3DCRT, 3-dimensional conformal radiation therapy; IMRT, intensity modulated radiation therapy; SB-IMRT, sequential boost-IMRT; SIB-IMRT, simultaneous integrated boost-IMRT; CCRT, concurrent chemoradiotherapy; CT, chemotherapy; $\mathrm{EQD}_{2}$, equivalent dose in 2 Gy fractions. 